\title{
Electrical Crystallization Mechanism and Interface Characteristics of Nanowire ZnO/Al Structures Fabricated by the Solution Method
}

\author{
Yi-Wei Tseng, ${ }^{1}$ Fei-Yi Hung, ${ }^{1}$ Truan-Sheng Lui, ${ }^{1}$ Yen-Ting Chen, ${ }^{1}$ \\ Ren-Syuan Xiao, ${ }^{1}$ and Kuan-Jen Chen ${ }^{1,2}$ \\ ${ }^{1}$ Department of Materials Science and Engineering, Institute of Nanotechnology and Microsystems Engineering, \\ Center for Micro/Nano Science and Technology, National Cheng Kung University, Tainan 701, Taiwan \\ ${ }^{2}$ The Instrument Center, National Cheng Kung University, Tainan 701, Taiwan
}

Correspondence should be addressed to Fei-Yi Hung, fyhung@mail.ncku.edu.tw

Received 7 November 2011; Accepted 1 March 2012

Academic Editor: Somchai Thongtem

Copyright (C) 2012 Yi-Wei Tseng et al. This is an open access article distributed under the Creative Commons Attribution License, which permits unrestricted use, distribution, and reproduction in any medium, provided the original work is properly cited.

Both solution nanowire $\mathrm{ZnO}$ and sputtered $\mathrm{Al}$ thin film on $\mathrm{SiO}_{2}$ as the wire-film structure and the Al film were a conductive channel for electrical-induced crystallization (EIC). Direct current (DC) raised the temperature of the Al film and improved the crystallization of the nanostructure. The effects of EIC not only induced $\mathrm{Al}$ atomic interface diffusion, but also doped $\mathrm{Al}$ on the roots of $\mathrm{ZnO}$ wires to form aluminum doped zinc oxide $(\mathrm{AZO}) / \mathrm{ZnO}$ wires. The $\mathrm{Al}$ doping concentration and the distance of the $\mathrm{ZnO}$ wire increased with increasing the electrical duration. Also, the electrical current-induced temperature was $\sim 211^{\circ} \mathrm{C}$ (solidstate doped process) and so could be applied to low-temperature optoelectronic devices.

\section{Introduction}

Zinc oxide $(\mathrm{ZnO})$ is a II-VI compound semiconductor with a hexagonal wurtzite structure. One-dimensional $\mathrm{ZnO}$ nanowires have the advantages of light extraction efficiency and different light-emitting mechanisms (UV emission, Green emission), so they have extensive applications in nano-optoelectronic devices $[1,2]$. Much research shows that highquality $\mathrm{ZnO}$ nanowires are a very important factor in nanodevices [3, 4]. Heat treatment [5] and doped-metal atoms [6-8] are effective and convenient methods to improve the physical properties (e.g, structure, magnetic, and p-n junction).

Synthetic methods for large area $1 \mathrm{D} \mathrm{ZnO}$ nanostructure, include hydrothermal synthesis [9], the Solid-Liquid-Solid method [10], and low-temperature solution method [11]. In addition, many researchers have shown that $\mathrm{Al}$ doped $\mathrm{ZnO}$ (AZO) nanostructures have excellent potential for applications $[7,12]$. The solution method is a low-temperature process, but doping metal atoms and concentration control are difficult. Also, the effects of $\mathrm{Al}$ atom doping using the solid-state method on $1 \mathrm{D} \mathrm{ZnO}$ nanowires have still not been reported, and in particular, the electric current-induced crystallization (EIC) process [13] is a solid-state method at room temperature and is worthy of further investigation.

In this study, we used the low-temperature solution method to synthesize uniform and ordered $\mathrm{ZnO}$ nanowires onto $\mathrm{ZnO} / \mathrm{Al}$ film on silicon substrate. The nanowires were grown preferentially in the c-axis direction (002) using a textured $\mathrm{ZnO}$ seeding layer [14]. The $\mathrm{Al}$ conductive layer was subjected to a constant voltage and current using electric current-induced crystallization (EIC). Then, EIC doped Al on the $\mathrm{ZnO}$ nanowire roots through thermoelectric effects (including joule heating and electromigration). Also, the structural characteristics of $\mathrm{Al}$ doped $\mathrm{ZnO}$ nanowires used solid-state EIC testing were studied.

\section{Experimental Procedures}

The low-temperature aqueous solution method was used to obtain zinc oxide $(\mathrm{ZnO})$ nanowires which were grown onto $\mathrm{ZnO} / \mathrm{Al}$ film on silicon substrate. This was followed by 


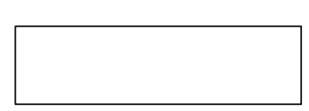

(a) Substrate clean
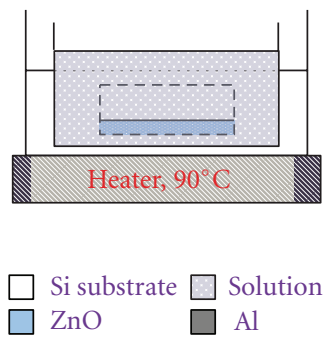

(c) Growth of $\mathrm{ZnO}$ nanowires

Figure 1: Schematic diagram of growth of $\mathrm{ZnO}$ nanowires.

aluminum doping using an electrical current (EIC). Figure 1 shows that the silicon substrate was cleaned using the Radio Corporation of America (RCA) method of cleaning and drying. Al film $(800 \mathrm{~nm})$ was deposited on the silicon substrate by thermal evaporation. After deposition of the Al film, there was a $100 \mathrm{~nm}$ thick layer of $\mathrm{ZnO}$ (as seed layer) grown by $\mathrm{RF}$ magnetron sputtering.

Aqueous solution of zinc nitrate $\left[\left(\mathrm{NO}_{3}\right)_{2} \cdot 6 \mathrm{H}_{2} \mathrm{O}\right](99.5 \%$, J. T. Baker) and hexamethylenetetramine [HMT; $\mathrm{C}_{6} \mathrm{H}_{12} \mathrm{~N}_{4}$ ] (99.9\%, Alfa Aersar) were mixed with an equal molar concentration. Then, the $\mathrm{ZnO} / \mathrm{Al}$ silicon substrate was put in the aqueous solution $(105 \mathrm{mM})$ at a temperature of $90^{\circ} \mathrm{C}$ for 1 hour. After this, the $\mathrm{ZnO}$ nanowires formed. Figure 2 shows that the Al film was a conductive channel to facilitate the electrical-induced crystallization at room temperature. EIC had doped $\mathrm{Al}$ on the $\mathrm{ZnO}$ thin film and $\mathrm{ZnO}$ nanowires. During the electrical process, a thermocouple wire was used to measure the sample surface temperature [13].

Before and after the electrical current testing, we analyzed the crystalline structure and orientation of the $\mathrm{ZnO}$ nanowires by X-ray, with angle $1.5^{\circ}$, scan speed $2 \% \mathrm{~min}$, and degree range from $30^{\circ} \sim 90^{\circ}$ [6-8]. Furthermore, the microstructure of the nanowires was investigated using a field emission scanning electron microscope (FE-SEM) and focused ion beam (FIB). The characteristics of the crosssection and the mechanism of $\mathrm{Al}$ atom migration with joule heating were investigated by transmission electron microscopy (TEM) and X-ray photoelectron spectroscopy (XPS).

\section{Results and Discussion}

A surface image and cross-section characteristics of the nanowire $\mathrm{ZnO} / \mathrm{Al}$ structures are shown in Figure 3. The $\mathrm{ZnO}$ nanowires had grown on the $\mathrm{ZnO} / \mathrm{Al}$ film uniformly (Figure 3(a)). From observations of the interfaces (Figure 3(b)), the $\mathrm{ZnO}$ nanowires had an excellent bonding interface with the seed layer and the growth direction was perpendicular to the surface. In addition, the average length of the nanowires was $910 \mathrm{~nm}$ and the average diameter was $89 \mathrm{~nm}$. The Al layer was a conductive layer and facilitated the electrical current-induced crystallization (EIC).

In fact, the EIC structure would break if the input voltage or power was too large $[13,15]$. So a power loading test of the nanowire $\mathrm{ZnO} / \mathrm{Al}$ structure was performed. The voltage $(V-)$ current $(I)$ curve is shown as Figure 4(a). It can be seen that the breakdown voltage of the Al film is $4 \mathrm{~V}(0.73 \mathrm{~A})$, and a voltage of $3.75 \mathrm{~V}$ and current of $0.68 \mathrm{~A}$ was selected for the EIC test (Figure 4(b)). Judging from past experience [13], the temperature variation (temperature curve upward or discontinuous) indicated the thermoelectric equilibrium was unstable. During 10 mins of EIC testing (the structure was not damaged), the surface temperature was stable starting from 6 mins and the average temperature of the nanowire $\mathrm{ZnO} / \mathrm{Al}$ structure was about $211^{\circ} \mathrm{C}$ by joule heating.

In order to understand the influence of EIC on the structural characteristics, the non-EIC specimens and the EIC specimens with $3.75 \mathrm{~V}$ for $10 \mathrm{~min}$ and $1 \mathrm{hr}$ were subjected to XRD analysis as shown in Figure 5.

The pattern of Figure $5(\mathrm{a})$ is the $\mathrm{ZnO} / \mathrm{Al}$ structure (no nanowires). Even when nanowires grew (Figure 5(b)), the $\mathrm{Al}$ film still had significant peaks at (111) and (311). After EIC, the intensity of the Al phase substantially decreased and the crystallization of $\mathrm{ZnO}$ increased (Figures 5(c) and 5(d), 002, 103) $[7,16,17]$. Notably, this result increased significantly with an increased EIC duration. When the time of EIC was increased to $1 \mathrm{hr}$, the crystallization of $\mathrm{ZnO}$ nanowires had improved. In general, as-deposited films are annealed (400 $600^{\circ} \mathrm{C}$ for 1 hour) to improve the crystalline characteristics. It is clear that the EIC method-induced thermal energy $\left(\sim 211^{\circ} \mathrm{C}\right)$ was insufficient to improve the crystallization of $\mathrm{ZnO}$ nanowires [14]. The ion diffusion of EIC helps to account for this result.

Figure 6 shows a bright field image of the nanowire $\mathrm{ZnO} / \mathrm{Al}$ structure after $\mathrm{EIC}$ for $10 \mathrm{~min}$. The $\mathrm{ZnO}$ nanowires had a crystalline structure and grew with a (002) orientation (Figure 5). In fact, the $\mathrm{ZnO}$ nanowires had already crystallized during the as-grown state but the degree of crystallization was low (as amorphous) [8-11, 14]. Notably, diffusion behavior of EIC was apparent in the interface zone between the $\mathrm{ZnO}$ nanowires (including the seed layer) and the Al layer. To understand the concentration of $\mathrm{Al}$ ions, points A (bottom seed layer) to $\mathrm{D}$ (the root of $\mathrm{ZnO}$ wires) were examined by EDX as shown in Figure 6. The bottom seed layer (point $\mathrm{A}, \mathrm{B}$ ) and root of the $\mathrm{ZnO}$ nanowires (point C, D) contained a higher zinc concentration and traces of aluminum $(0.198 \sim 0.236$ at.\%). When the examined zone approached the $\mathrm{ZnO}$ nanowires (points $\mathrm{C}$ and $\mathrm{D}$ ), both zones contained mainly zinc, oxygen, and aluminum (concentration value was similar). The concentration data proves that the nanowires not only had identical chemical compositions, but also underwent some ion diffusion at the root zones.

EDX is a semi-quantitative analysis, so the electrical current time of the nanowire $\mathrm{ZnO} / \mathrm{Al}$ structure was increased from $10 \mathrm{~min}$ to 1 hour and then XPS was performed. For the un-EIC nanowire $\mathrm{ZnO} / \mathrm{Al}$ structure, only zinc and oxygen ions were detected at the root of the wire and seed layer. After 


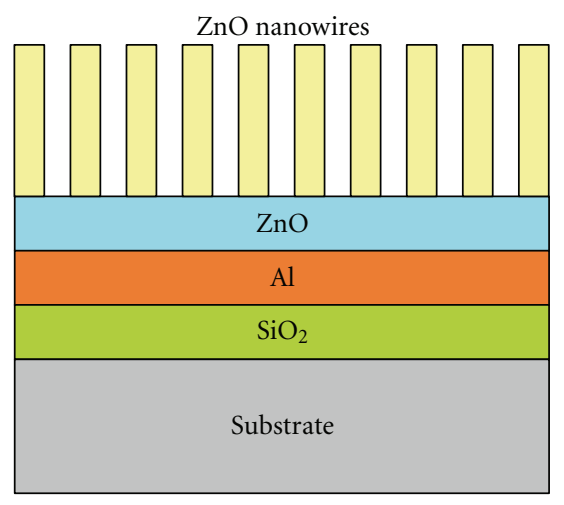

(a)

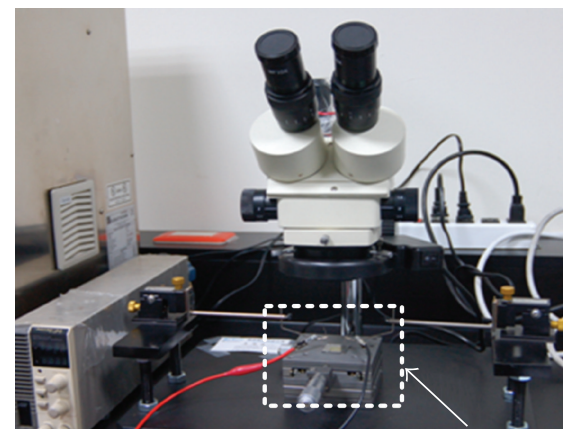

(c)

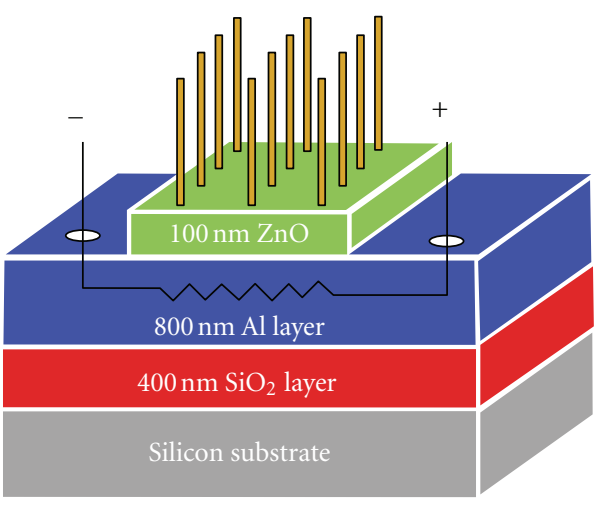

(b)

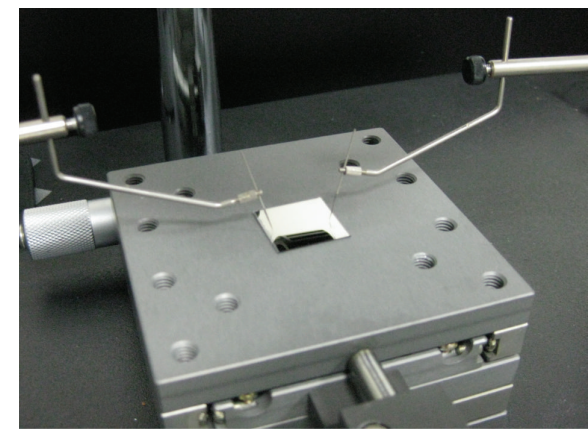

(d)

FIGURE 2: Schematic diagram of nanostructure and electrical current equipment. (a) Multinanostructure, (b) electrical induced crystallization (EIC) mechanism, (c) in situ electrical current equipment, and (d) magnification of the dotted box in (c).

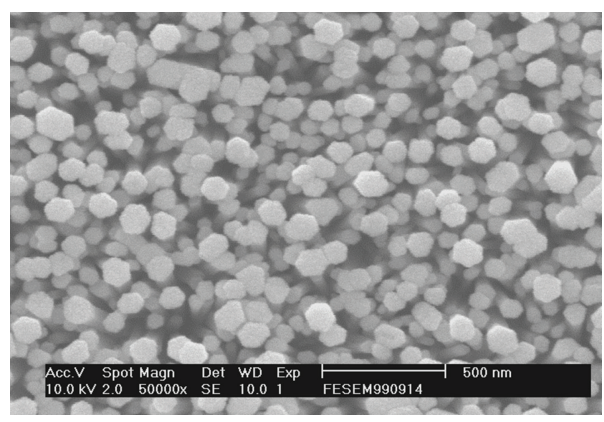

(a)

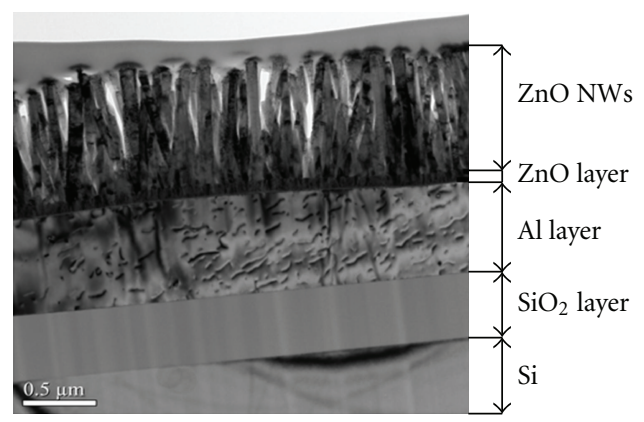

(b)

Figure 3: Observations of nanowire $\mathrm{ZnO} / \mathrm{Al}$ structures. (a) Surface characteristics and (b) interface structure of cross-section.

1 hour of EIC testing, aluminum ions were detected at the root zone of the wire and seed layer (Figure 7). Meanwhile the zinc content gradually decreased which indicates that Auger electrons had got into the interface between the $\mathrm{ZnO}$ seed layer and the aluminum layer. After that, the aluminum content increased and an aluminum layer was detected. To put it more precisely, the atom distributions were regular and were similar to those in Figure 6. This figure clearly shows that the root of the $\mathrm{ZnO}$ nanowires not only contained zinc and oxygen ions, but also possessed some aluminum ions (the nonelectrical current sample had no aluminum ions, accuracy of XPS is 0.001 at.\%). In particular, the diffusion path of the aluminum ions was about $480 \mathrm{~nm}$ and their average concentration ions was about at $(0.757$ at.\%) in the root zone of the $\mathrm{ZnO}$ nanowires.

After EIC, the intensity and concentration of $\mathrm{Al}$ ions substantially increased in the root zone of the nanowires. The main reason is that the EIC caused the micro-Al ions embedded into $\mathrm{ZnO}$ structure to form an AZO structure which improved the crystallization of $\mathrm{ZnO}$ nanowires that combined ion migration with joule heating. This result is similar to the metal doping mechanism in our previous report 


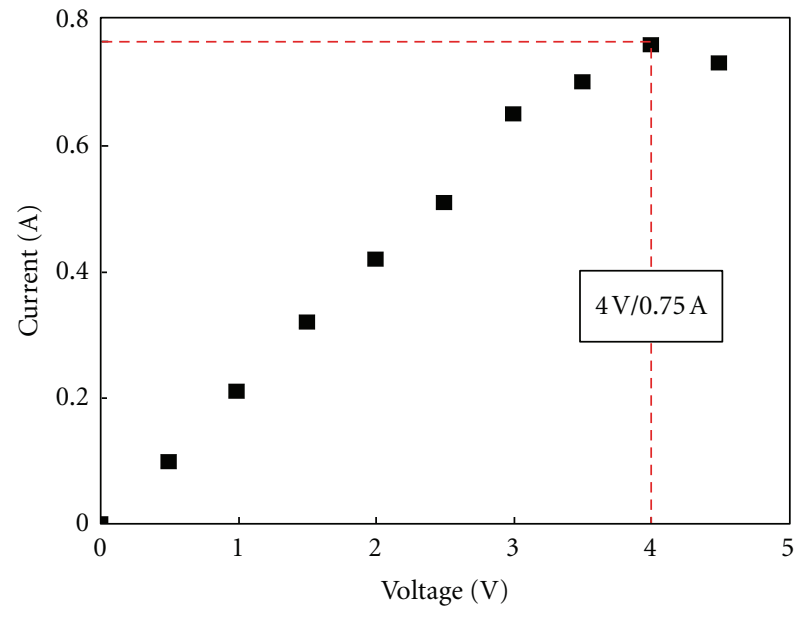

(a)

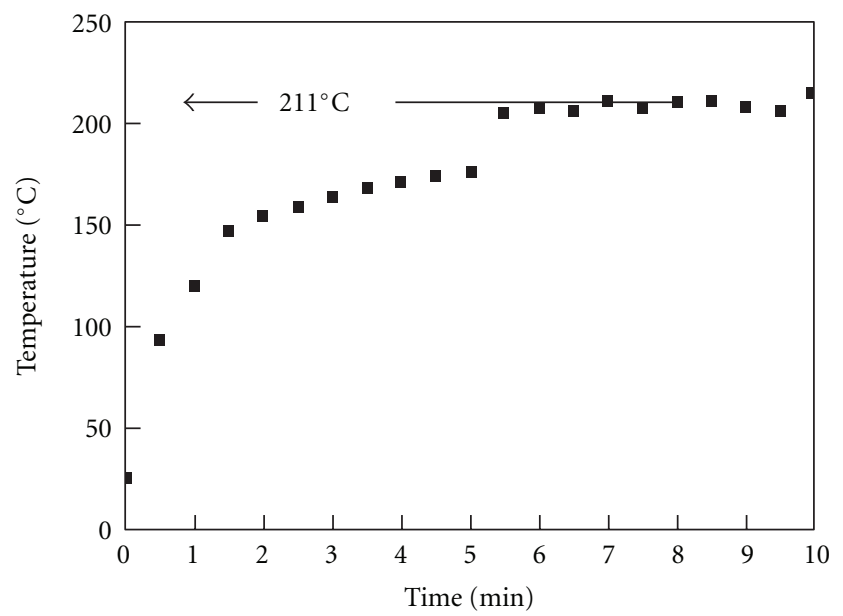

(b)

Figure 4: (a) Voltage ( $V$-) current $(I)$ curve of structures and (b) surface temperature curve of thermal induced at $3.75 \mathrm{~V}$ for 10 mins.

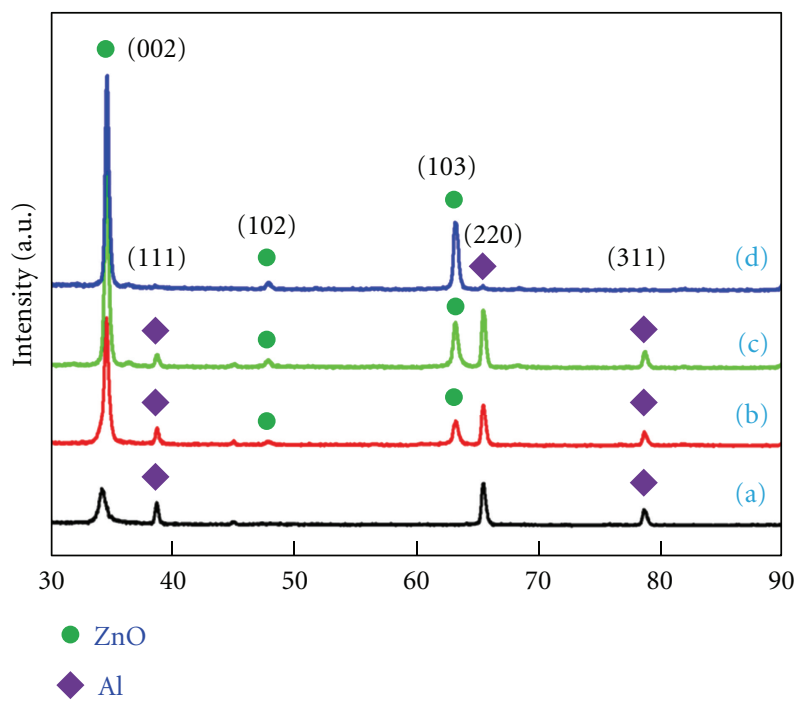

Figure 5: XRD patterns of specimens. (a) $\mathrm{ZnO} / \mathrm{Al} / \mathrm{SiO}_{2} / \mathrm{Si}$ (un-nanowires), (b) $\mathrm{ZnO} \mathrm{NWs}-\mathrm{ZnO} / \mathrm{Al} / \mathrm{SiO}_{2} / \mathrm{Si}$ (un-EIC), (c) EIC process testing 10 mins, $\mathrm{ZnO} \mathrm{NWs}-\mathrm{ZnO} / \mathrm{Al} / \mathrm{SiO}_{2} / \mathrm{Si}$ (EIC $10 \mathrm{~min}$ ), (d) $\mathrm{ZnO}$ $\mathrm{NWs}-\mathrm{ZnO} / \mathrm{Al} / \mathrm{SiO}_{2} / \mathrm{Si}$ (EIC for 1 hour).

$[6-8,13]$. Based on the above results, it is confirmed that the improvement in crystallization can be attributed to the EIC and ion diffusion.

From the EIC data, aluminum migration was the main crystallization mechanism which improved the opto-electronic properties of the nanowire $\mathrm{ZnO} / \mathrm{Al}$ structure. A relevant report $[5,18]$ showed that metal ions would gradually diffuse under a higher annealing temperature leading to an improvement in film conductivity. In fact, the present structure with electrical current crystallization only needed relatively little energy to make the metal ions migrate and improve the quality of the structure (Figure 8). In short, the $\mathrm{ZnO}$ nanowires can be doped by EIC. The crystallization

\begin{tabular}{cccc}
\hline & $\mathrm{Al}$ & $\mathrm{O}$ & $\mathrm{Zn}$ \\
\hline $\mathrm{A}$ & $1.058 \%$ & $49.417 \%$ & $49.523 \%$ \\
$\mathrm{~B}$ & $0.474 \%$ & $49.888 \%$ & $49.637 \%$ \\
$\mathrm{C}$ & $0.236 \%$ & $50.344 \%$ & $49.457 \%$ \\
$\mathrm{D}$ & $0.198 \%$ & $49.45 \%$ & $50.312 \%$ \\
\hline
\end{tabular}

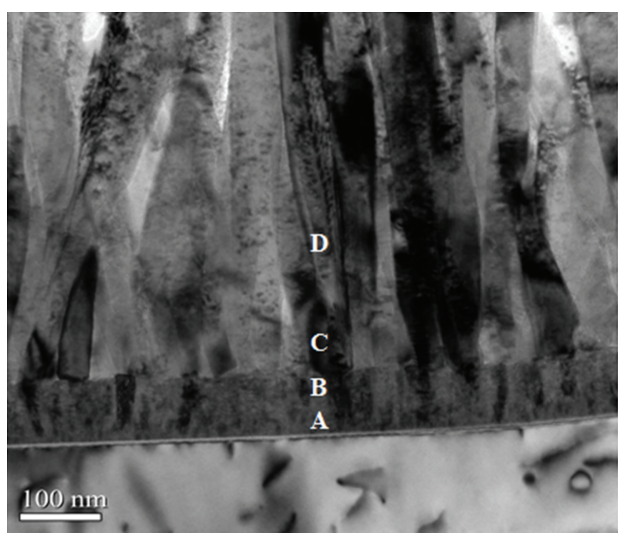

Figure 6: Ion diffusion of nanowire $\mathrm{ZnO} / \mathrm{Al}$ structure: cross-section of structure and atom content from point $A$ to point $D$.

mechanism using the electrical current method is a solidstate method. Therefore, the stability of upper $(\mathrm{ZnO})$ and lower (AZO) nanowires can lead to excellent 1D structural properties.

\section{Conclusion}

The electrical-induced crystallization (EIC) possessed excellent save energy and could be applied to low-temperature applications. The crystallization of the nanowire $\mathrm{ZnO} / \mathrm{Al}$ structure on a Si substrate was enhanced using EIC. Owing to the thermoelectric effect, the $\mathrm{Al}$ ions diffused into both 


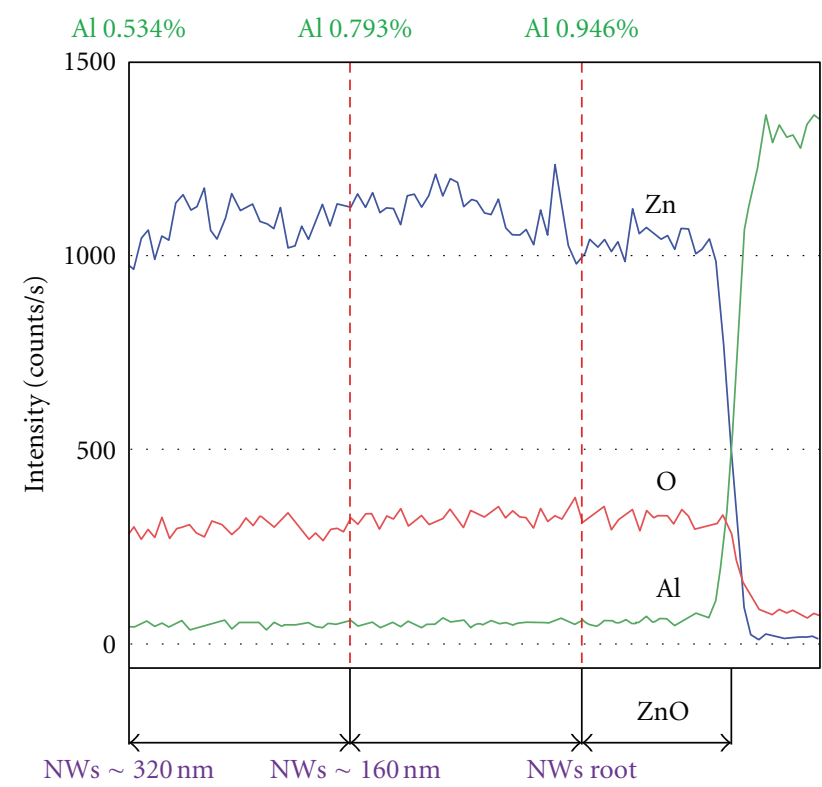

FIGURE 7: XPS depth profiles of nanowire $\mathrm{ZnO} / \mathrm{Al}$ structure after electrical current testing (zero point: NWs root). After testing, the root of the $\mathrm{ZnO}$ nanowires had some $\mathrm{Al}$ ions and the concentration of $\mathrm{Al}$ ions was about (0.757 at.\%) (nonelectrical current had no $\mathrm{Al}$ ions).

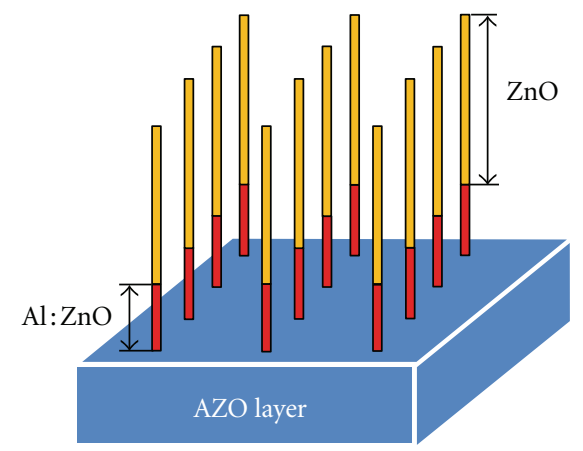

FIGURE 8: Schematic diagram of electrical current-induced crystallization and diffusion. After EIC, the induced joule-heat and $\mathrm{Al}$ ion migration from a bottom AZO film and AZO nanowires through doping and recrystallization.

the $\mathrm{ZnO}$ seed layer and the root zone of the nanowires. The upper $(\mathrm{ZnO})$ and lower (AZO) nanowire was a composite wire that had unique optoelectronic properties and was confirmed as having contributed to the $\mathrm{ZnO} / \mathrm{Al}$ structure.

\section{Acknowledgments}

The authors are grateful to National Cheng Kung University, the Center for Micro/Nano Science and Technology (D1012700) and NSC 100-2221-E-006-094 for the financial support.

\section{References}

[1] H. Q. Liang, L. Z. Pan, and Z. J. Liu, "Synthesis and photoluminescence properties of $\mathrm{ZnO}$ nanowires and nanorods by thermal oxidation of Zn precursors," Materials Letters, vol. 62, no. 12-13, pp. 1797-1800, 2008.

[2] S. Hejazi, H. R. Hosseini, and M. S. Ghamsari, "The role of reactants and droplet interfaces on nucleation and growth of $\mathrm{ZnO}$ nanorods synthesized by vapor-liquid-solid (VLS) mechanism," Journal of Alloys and Compounds, vol. 455, no. 1-2, pp. 353-357, 2008.

[3] Q. X. Zhao, P. Klason, and M. Willander, "Growth of $\mathrm{ZnO}$ nanostructures by vapor-liquid-solid method," Applied Physics A, vol. 88, no. 1, pp. 27-30, 2007.

[4] J. S. Lee, M. S. Islam, and S. Kim, "Photoresponses of $\mathrm{ZnO}$ nanobridge devices fabricated using a single-step thermal evaporation method," Sensors and Actuators B, vol. 126, no. 1, pp. 73-77, 2007.

[5] T. Li, C. S. Ong, T. S. Herng et al., "Surface ferromagnetism in hydrogenated-ZnO film," Applied Physics Letters, vol. 98, Article ID 152505, 3 pages, 2011.

[6] K. J. Chen, F. Y. Hung, S. J. Chang, and Z. S. Hu, "Microstructures, optical and electrical properties of In-doped $\mathrm{ZnO}$ thin films prepared by Sol-Gel method," Applied Surface Science, vol. 255, no. 12, pp. 6308-6312, 2009.

[7] K. J. Chen, T. H. Fang, F. Y. Hung et al., "The crystallization and physical properties of Al-doped $\mathrm{ZnO}$ nanoparticles," Applied Surface Science, vol. 254, no. 18, pp. 5791-5795, 2008.

[8] K. J. Chen, F. Y. Hung, Y. T. Chen, S. J. Chang, and Z. S. $\mathrm{Hu}$, "Surface characteristics, optical and electrical properties on Sol-Gel synthesized Sn-doped ZnO thin film," Materials Transactions, vol. 51, no. 7, pp. 1340-1345, 2010.

[9] Y. J. Kim, A. Hadiyawarman, A. Yoon, M. Kim, G. C. Yi, and C. Liu, "Hydrothermally grown $\mathrm{ZnO}$ nanostructures on fewlayer graphene sheets," Nanotechnology, vol. 22, no. 24, Article ID 245603, 2011.

[10] M. Ahmad and J. Zhu, " $\mathrm{ZnO}$ based advanced functional nanostructures: synthesis, properties and applications ," Journal of Materials Chemistry, vol. 21, pp. 599-614, 2011.

[11] T. Jun, K. Song, Y. Jeong et al., "High-performance low-temperature solution-processable $\mathrm{ZnO}$ thin film transistors by microwave-assisted annealing," Journal of Materials Chemistry, vol. 21, no. 4, pp. 1102-1108, 2011.

[12] J. Kim, J. H. Yun, S. W. Jee et al., "Rapid thermal annealed Aldoped ZnO film for a UV detector," Materials Letters, vol. 65, no. 4, pp. 786-789, 2011.

[13] F. Y. Hung, "Crystallization mechanism and raman characteristics of $\mathrm{ZnO} / \mathrm{In} / \mathrm{ZnO}$ thin film using an electrical current method," Materials Transactions, vol. 52, no. 6, pp. 1138-1141, 2011.

[14] K. J. Chen, F. Y. Hung, S. J. Chang, and Z. S. Hu, "The crystallized mechanism and optical properties of sol-gel synthesized $\mathrm{ZnO}$ nanowires," Journal of the Electrochemical Society, vol. 157, no. 3, pp. H241-H245, 2010.

[15] C. C. Chou, F. Y. Hung, and T. S. Lui, "Role of crystallized phases in sheet resistance of amorphous AgInSbTe chalcogenide film," Scripta Materialia, vol. 56, no. 12, pp. 1107-1110, 2007.

[16] H. C. Huang and T. E. Hsieh, "Highly stable precursor solution containing $\mathrm{ZnO}$ nanoparticles for the preparation of $\mathrm{ZnO}$ thin film transistors," Nanotechnology, vol. 21, no. 29, Article ID 295707, 2010. 
[17] H. S. Kang, J. S. Kang, S. S. Pang, E. S. Shim, and S. Y. Lee, "Variation of light emitting properties of $\mathrm{ZnO}$ thin films depending on post-annealing temperature," Materials Science and Engineering B, vol. 102, no. 1-3, pp. 313-316, 2003.

[18] C. Periasamy and P. Chakrabarti, "Effect of annealing on the characteristics of nanocrystalline $\mathrm{ZnO}$ thin films," Science of Advanced Materials, vol. 3, no. 1, pp. 73-79, 2011. 

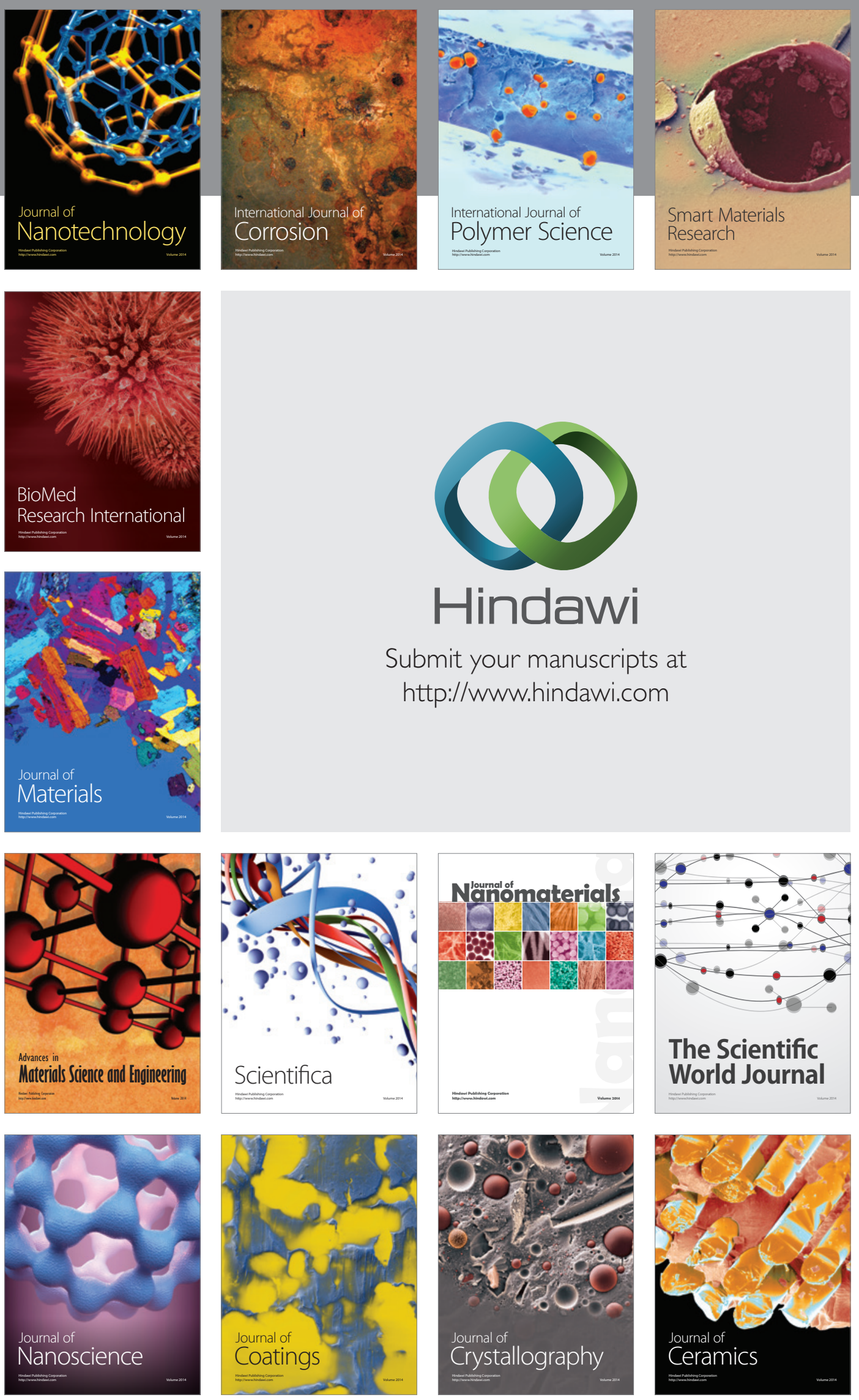

The Scientific World Journal

Submit your manuscripts at

http://www.hindawi.com

\section{World Journal}

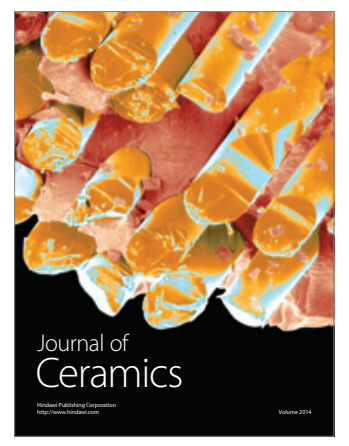

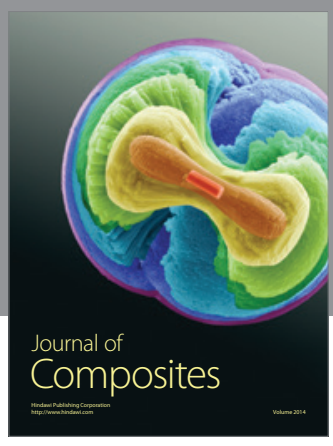
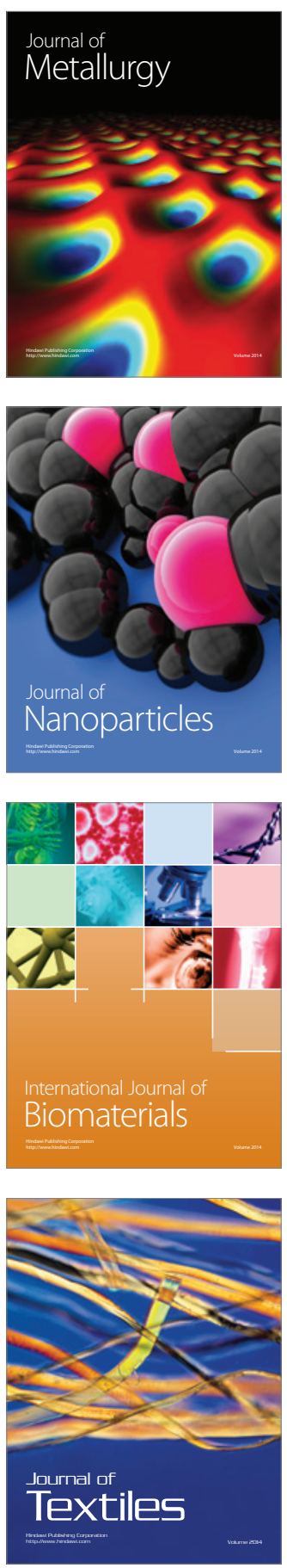